\title{
Use of Tension free Trans Obturator Tape in treatment of Stress Urinary Incontinence: a Recent Gold Standard Approach
}

\author{
Dr. Sweety Bhuriya ${ }^{1}$, Dr. Vyas Rupa C. ${ }^{2-A}$, Dr. Shah Sapana R. ${ }^{2-B}$, \\ Dr. Mona Gamit ${ }^{2-C}$, \\ ${ }^{I}$ (Resident Doctor, Department of Obstetrics and Gynecology Smt. N.H.L. Municipal medical college and Sheth \\ V.S. General Hospital) \\ ${ }^{2 A}$ (Assistant professor, Department of Obstetrics and Gynecology, Smt. N.H.L. Municipal medical college and \\ Sheth V.S. General Hospital) \\ ${ }^{2 B}$ (Associate professor and head of unit, Department of Obstetrics and gynecology, Smt. N.H.L. Municipal \\ medical college and Sheth V.S. General Hospital) \\ ${ }^{2 C}$ (Resident Doctor, Department of Obstetrics and Gynecology, Smt. N.H.L. Municipal medical college and \\ Sheth V.S. General Hospital)
}

\section{Introduction}

According to International Continence Society (ICS), urinary incontinence is defined as"any involuntary loss of urine that is a social or hygienic problem for the individual"1. SUI is most common type of urinary incontinence with incidence between $13 \%-50 \%$ increasing in elderly population ${ }^{2}$. In $30 \%$ of incontinent women, there is a combination of stress and urge incontinence $e^{3,4}$.

The surgical treatment of female SUI, due to urethral hypermobility, changed drastically a few years ago when a novel concept of tension free mid-urethral support was described by Ulmsten and Petros ${ }^{5}$. Karram et $\mathrm{al}^{6}$ described that tension-free vaginal tape (TVT) is a safe and successful technique, but serious though rare complications including vascular and bowel injuries have been reported during this procedure while passing the sling through the retropubic space ${ }^{7,8}$. In France, in 2001 Delorme found a technique of inserting the tape, which passes through the obturator foramen ${ }^{9}$.

The space that the needle passes through has been extensively studied and has been found to be a very safe. The mean operative time is significantly shorter in the transobturator sling and risk of bladder injury and postoperative urinary retention are considerably lesser than other sling procedures ${ }^{10}$.

\section{Materials And Method}

This was a retrospective study to see the clinical outcome in patients of SUI treated with transobturator sling. The study group included patients attending the gynecology OPD at a tertiary care teaching hospital from October 2010 to December 2013. It was carried out to see the efficacy and safety of TOT in SUI and its intraoperative parameters, per-operative and postoperative complications.

All patients attending gynecology OPD at a tertiary care teaching hospital, who complained of involuntary loss of urine on coughing, sneezing, laughing, straining, or any other action suggestive of rise in intra-abdominal pressure, were included in study group. Detailed history taking and physical examination was carried out. Only non-pregnant patients with a history of genuine stress incontinence, without history of any previous corrective surgery for the same and the patients for whom no other gynecological surgery (e.g. surgery for pelvic organ prolapse) was planned in the same sitting were recruited in this study.

All the patients with SUI and a positive Bonney's test were counseled regarding the available modes of management including medical and surgical options. Patients who were ready to undergo surgery, either to start with or after failure in relief of symptoms after a trial of physical and/or medical treatment were finally selected for TOT placement.

Transobturator sling was applied using a TOT by outside-in technique. In transobturator (TOT) approach, through small incisions placed in the groins and in the vagina under the urethra, the tape can be placed under the urethra, passing needles through the obturator foramen. The duration for the surgical procedure was recorded for every patient. The blood loss during surgery was assessed. Postoperative antibiotics and analgesics 
were given. Foley's catheter was kept for 24 hours. Patients were discharged when they had passed the urine freely and no complaints of urinary retention. The duration of their hospital stay was recorded.

All patients were advised to avoid squatting position and intercourse for one month. They were told to use european toilet seat while micturition and defecation. They were advised to take an adequate fluid intake to prevent urinary infections and constipation. The patients were called for a follow-up at 2 weeks after surgery and then at 3 and 6 months. At the follow-up visits, they were asked about the relief of symptoms of urinary incontinence, pain, and their satisfaction with the surgical outcome.

\section{Results}

The mean age of the patients operated for SUI was 44.2 years (range 30-70 years). Out of the 28 patients, 20 were premenopausal (71.4\%) and 8 were postmenopausal (28.6\%). Out of 28 women, only $1(3.5 \%)$ was a nulliparous woman, $3(10.7 \%)$ were primiparous women and $24(85.8 \%)$ were multiparous women. The mean duration of surgery was 22.38 minutes, and the mean blood loss was $72.25 \mathrm{ml}$, which was calculated by using pre-weighed swabs. There was no per-operative complication. One patient had extrusion of tape into vagina after 15 days. All the patients were discharged between 24 and 72 hours after surgery.

Out of 28 patients included in the study, 26 transobturator slings were successful and 2 had a surgical failure $(7.1 \%)$ in form of persistence of stress incontinence after procedure. Total success rate of transobturator sling fixation in the study was $92.9 \%$. No definite cause could be found for failure of sling fixation in these two cases. Out of 28 cases, $24(85.8 \%)$ ) patients were completely satisfied with the surgical outcome, whereas after 6 month follow-up 2 patients (7.1\%) were partially satisfied, had mild degree of incontinence and required occasional use of pads and 2(7.1\%) had persistent incontinence, and were unsatisfied with the surgical outcome.

\section{Discussion}

In our series, we treated patients of genuine stress incontinence with the outside-in TOT procedure which is a simple technique with a very short learning period. Success rate of TOT application was $92.9 \%$ cases and it was failed in $7.1 \%$ cases in present study. In a series of 40 patients, Delrome in 2001 reported $100 \%$ success rate, 39 patients had no incontinence post-procedure and 1 patient had improvement in symptoms of incontinence ${ }^{9}$. In 2004, DeTayrac reported a 1-year cure rate of $84 \%$ with the TOT technique ${ }^{10}$. In 2005, Spinosa reported subjective complete and partial satisfaction rates of $92.3 \%$ and $4.2 \%$, respectively in a series of 117 patients with a median follow-up of 16.3 months $^{11}$. Taweel et al. reported a $92 \%$ cure rate after 1 year and $85 \%$ after 2 year by an objective assessment and a patient satisfaction rate of $88 \%$ at 1 year by subjective assessment $^{12}$

The mean age of the women operated for SUI under present study was 44.2 years ( range 30-70 years). The mean age of patients reported by Taweel in his study was $52 \pm 9$ years (range 34-70 years) ${ }^{12}$. Moore et al. in their study had patients with an average age of 56.8 years with an SD of $11.7^{13}$.

In present study, the mean operative time was 22.38 minutes, and mean intra-operative blood loss was $72.25 \mathrm{ml}$. Taweel reported mean surgery duration of 18 minutes and mean intra-operative blood loss of $57 \mathrm{ml}^{12}$. Moore et al. reported the mean operative time for TOT placement as 12.4 minutes and mean intra-operative blood loss of $36 \mathrm{ml}$ in his study ${ }^{13}$.

All the patients were discharged between 24 and 72 hours after surgery- mean hospitalization time was 1.4 days (range 1-3 days). Purnichescu et al. from France reported mean duration of hospitalization in the cases of isolated TOT as 1.25 days $^{14}$

None of our patients had mixed or urge incontinence. None of the patient required cystoscopic examination during or after surgery, as there was no bladder injury. Abdel-Fattah and colleagues described that injury to bladder and urethra only occurred with the outside-in technique, after performing 390 cases of TOT by different routes ${ }^{15}$. Although urine retention and voiding dysfunction are thought to be less common after the transobturator approach, the rates vary from $0 \%$ to $15.6 \%{ }^{16}$. In our series, none of the patient developed urinary retention, except one case had transient retention that was relieved by recatheterization and next day she voided successfully. One patient had mesh extrusion after 15 days. Vaginal laceration if remained unrecognized may predispose patients to mesh extrusion. While bringing out the needle through vagina, it is recommended to see the lateral vaginal wall after passing the needle through transobturator foramen ${ }^{17}$. Tape adjustment without any 
tension or any contact with the urethra is an important step to avoid erosion and voiding dysfunction. No patient in this study had vascular, neural, or bowel injury. None of the patient complained pain in thigh in present study, which corresponds with findings of a meta-analysis by Latthe et al.; that the outside-in TOT technique is usually not associated with this specific symptom ${ }^{18}$.

Obstructive voiding dysfunction is less likely to occur with the TOT, as it is positioned horizontally across the urethra, and it gives less chance for static urethral kinking and the urethral obstruction. Also it is not possible anatomically to over tighten the tape in TOT procedure. There is hardly any reported incidence of urinary retention because of mechanical obstruction, while obstructive voiding dysfunction is the most commonly reported complication of some other mid urethral sling placements like TVT. In present series, none of the patient developed urethral obstruction requiring complete or even partial tape release.

Another advantage of the TOT as compared with other mid-urethral sling procedures is the lesser incidence of urge incontinence. In the transobturator approach, tape crosses the obturator foramen, obturator externus and internus muscles, and fascia. The tape reproduces the natural suburethral suspension by reinforcing the rotational pivot point, corrects incontinence and spares the rertropubic space. Advantage of sparing the retropubic space preserves periurethral nerve fibers associated with urethral function and stability, also eliminates the risk of major bowel, neural, and vascular complications which have been reported with the TVT. In present study, there was no incidence of urge incontinence.

\section{Conclusion}

Concluding the analysis of our data, the out-in TOT procedure is a very safe technique, which can be used regularly in daily clinical practice in order to treat female SUI. In accordance with the international literature, it seems less dangerous and easier to learn than the retro pubic way. The high percentage of successfully treated cases, and even in the patients who need other vaginal surgical procedures confirms that it can be widely employed to treat urinary stress incontinence. TOT should be part of the technical skills of every surgeon performing pelvic floor reconstructive surgery. Cystoscopy is not mandatorily required for TOT. It gives a high success rate and good patient satisfaction.

\section{References}

[1]. Abrams P, Cardozo L, Fall M, et al. The standardisation of terminology of lower urinary tract function: report from the Standardisation Sub-committee of the International Continence Society. Am J Obstet Gynecol 2002;187:116-26.

[2]. Cerruto MA, D'Elia C, Aloisi A, et al. Prevalence, Incidence and obstetric factors' Impact on female urinary incontinence in Europe: A Systematic Review Urol Int 2012 Aug 3.(Epub ahead of print)

[3]. Davila GW, Guerette N. Current treatment options for female urinary incontinence - a review. Int J Fertil Womens Med. 2004; 49:102-12.

[4]. RichterHE., Burgio KL, Goode PS, et al Non-surgical management of stress urinary incontinence: ambulatory treatments for leakage associated with stress. Clin Trials.; 2007;4;:92-101.

[5]. Ulmsten U, Petros P. Intravaginal slingplasty (IVS): an ambulatory surgical procedure for treatment of female urinary incontinence. Scand J Urol Nephrol 1995;29:75-82.

[6]. Karram M, Segal L, Vassallo J, et al. Complications and unwanted effects of the tension-free vaginal tape procedure. Obstet Gynecol 2003;101:929-32.

[7]. Bafghi A, Iannelli A, Trastour C, et al. Bowel perforation as late complication of tension-free vaginal tape. J Gynecol Obstet Biol Reprod (Paris) 2005;34:606-7.

[8]. Hermieu JF, Messas A, Delmas V, et al. Bladder injury after TVT transobturator. Prog Urol 2003;13:115-7.

[9]. Delorme E. Transobturator urethral suspension: mini-invasive procedure in the treatment of stress urinary incontinence in women. Prog Urol 2001;11:1306-13.

[10]. DeTayrac R, Deffieux X, Droupy S et al. A prospective randomized trial comparing tension-free vaginal tape and transobturator suburethral tape for surgical treatment of stress urinary incontinence. Am J Obstet Gynecol. 2004;190:602-8.

[11]. Spinosa JP, Dubuis PY. Suburethral sling inserted by the transobturator route in the treatment of female stress urinary incontinence: Preliminary results in 117 cases. Eur J Obstet Gynecol Reprod Biol. 2005;123:212-7.

[12]. Taweel WA, Rabah DM. Transobturator tape for female stress incontinence: Follow-up after 24 months. Can Urol Assoc J. 2010;4:33-6.

[13]. Moore RD, Miklos JR. Argentina: Buenos Aires; 2006. Mar 29, Transobturator Sling: Combined analyses of 1 year follow up in 9 countries with 266 patients: XV Congress of the International Society for Gynecologic Endoscopy. April 1.

[14]. Purnichescu V, Cheret-Benoist A, Eboué C, Von Theobald P. Surgical treatment for female stress urinary incontinence by transobturator tape (outside in). Study of 70 cases. J Gynecol Obstet Biol Reprod (Paris) 2007;36:451-8.

[15]. Abdel-Fattah M, Ramsay I, Pringle S, Bjornsson S, Hardwick C, Tierney J, et al. Transobturator suburethral tapes in the management of urinary incontinence: Success, safety and impact on sexual life. Gynecol Surg. 2007;4:267-73. 
[16]. Fischer A, Fink T, Zachmann S, et al. Comparison of retropubic and outside-in transobturator sling systems for the cure of female genuine stress urinary incontinence. Eur Urol 2005;48:799-804.

[17]. David-Montefiore E, Frobert JL, Grisard-Anaf M, et al. Peri-operative complications and pain after the suburethral sling procedure for urinary stress incontinence: a French prospective randomised multicentre study comparing the retropubic and transobturator routes. Eur Urol 2006;49:133-8.

[18]. Latthe PM, Patodi M, Constantine G. Transobturator tape procedure in stress urinary incontinence: UK experience of a district general hospital. J Obstet Gynecol. 2007;27:177-80. 